\title{
Effect of composition on molecular alignment in polyethylene terephthalate copolymers
}

\author{
C. S. Wang* and G. S. Y. Yeh \\ Macromolecular Science and Engineering Program, Department of Chemical Engineering, \\ The University of Michigan, Ann Arbor, Michigan 48109, USA \\ (Received 12 March 1981; revised 8 June 1981)
}

\begin{abstract}
In this study molecular alignment in copolymers of polyethylene terephthalate (PET) and $p$ hydroxybenzoic acid (PHB) was examined by means of differential radial distribution function (DRDF) analysis of wide angle $X$-ray scattering data. The study was carried out using two representative copolymers with the PHB content of 30 and $60 \mathrm{~mol} \%$. The DRDF curves for the amorphous and the partially crystalline samples of these copolymers showed periodic intermolecular peaks up to various radial distances. The appearance of these peaks at $\sim 5 \AA$ periodicity suggested the existence of more-orless parallel chain segments in the copolymers. The extent of the lateral molecular organization was $\sim 15$ and $30 \AA$ for the amorphous copolymers containing 30 and $60 \mathrm{~mol} \%$ PHB, respectively. A substantial structural difference was therefore shown for the copolymers in this composition range. The $D R D F$ curve for the amorphous copolymer with $30 \mathrm{~mol} \%$ PHB was found to be very similar to that for the previously reported glassy PET with $0 \mathrm{~mol} \%$ PHB, indicating that the two materials had almost the same intermolecular structure. The structural information revealed by these $D R D F$ results was in agreement with the various property changes caused by varying PHB contents of the copolymers.
\end{abstract}

Keywords Polymers; liquid crystalline; differential radial distribution function; wide angle $\mathrm{X}$-ray scattering; molecular alignment; polyethylene terephthalate; copolymers

\section{INTRODUCTION}

Recently Jackson and Kuhfuss ${ }^{1}$ prepared a series of random copolymers with interesting properties. The copolymers were obtained by incorporating various amounts of $p$-hydroxybenzoic acid (PHB) into the backbone of polyethylene terephthalate (PET). The preparation involved acidolysis of the polyester with $p$ acetoxybenzoic acid and polycondensation through the acetate and carboxyl groups. It was found that the copolymers with PHB contents over 30 to $80 \mathrm{~mol} \%$ gave turbid melts, low melt viscosities, and readily shearinduced anisotropic solids. The unusual properties were attributed to the nematic liquid crystalline nature of the polymer melts by McFarlane, Nicely, and Davis ${ }^{2}$. The mesophase was a result of the possible improvement in alignment of polymer chains due to the presence of planar PHB moieties in the copolymers.

In this study the alignment of chain segments in the new copolymers was examined by means of differential radial distribution function (DRDF) analysis of wide angle $\mathrm{X}$-ray scattering (WAXS) intensities. The study provides information leading towards a better understanding of polymer properties in molecular terms. It is part of our work to ascertain the nature of the molecular organization in 'amorphous' molten and glassy polymers.

The DRDF analysis was applied to the amorphous and the partially crystalline copolymers containing $30 \mathrm{~mol} \%$ PHB (70 PET/30 PHB) and $60 \mathrm{~mol} \%$ PHB (40 PET/60

* Present address: Polymers Department, General Motors Research Laboratories, Warren, Michigan 48090, USA
PHB). The two compositions are representative since the interesting properties of the copolymer series started to appear when the PHB content was just over $30 \mathrm{~mol} \%$ and became most pronounced at $60 \mathrm{~mol} \%$. The DRDF results of the copolymers were compared with that of the base polyester, i.e., polyethylene terephthalate containing 0 $\mathrm{mol} \%$ PHB (100 PET/0 PHB) to reveal the structural change caused by varying the composition. The structure of the glassy and the partially crystallized 100 PET/0 PHB has been studied previously using the $D R D F$ analysis by Longman, Sheldon, and Wignall ${ }^{3}$ and Gupta and $\mathrm{Yeh}^{4}$.

Some $D R D F$ results of the amorphous $40 \mathrm{PET} / 60 \mathrm{PHB}$ have been reported in a preliminary communication ${ }^{5}$.

\section{EXPERIMENT AND ANALYSIS}

The 70 PET/30 PHB and 40 PET/60 PHB copolymers used in this study were provided by Dr W. J. Jackson, Jr., of Tennessee Eastman Company. For each copolymer both amorphous and partially crystalline samples of approximately $0.6 \mathrm{~mm}$ thick were prepared. The amorphous samples were compression moulded at $295^{\circ} \mathrm{C}$ and rapidly quenched in ice water ${ }^{2}$. The partially crystallized samples were prepared by subsequent annealing of the amorphous sheets in a vacuum oven. Pertinent information on the preparation and properties of the four copolymer samples is given in Table 1 .

The procedures employed for WAXS data collection and analysis have been described in detail elsewhere ${ }^{4-6}$. The X-ray scattering measurements were made on a Philips Norelco diffractometer using monochromatized $\mathrm{Cu} \mathrm{K} \alpha$ radiation (wavelength $\lambda=\mathrm{a} .542 \AA$ ). The WAXS 
Table 1 Description of the preparation and properties of the copolymer samples

\begin{tabular}{lrrrr}
\hline Sample & 1 & 2 & 3 & 4 \\
\hline $\begin{array}{l}\text { Composi- } \\
\text { tion }\end{array}$ & $\begin{array}{r}70 \mathrm{PET} / \\
30 \mathrm{PHB}\end{array}$ & $\begin{array}{r}40 \mathrm{PET} / \\
60 \mathrm{PHB}\end{array}$ & $\begin{array}{l}70 \mathrm{PET} / \\
30 \mathrm{PHB}\end{array}$ & $\begin{array}{l}40 \mathrm{PET} / \\
60 \mathrm{PHB}\end{array}$ \\
$\begin{array}{l}\text { Thermal } \\
\text { history }\end{array}$ & quenched & quenched & $\begin{array}{l}\text { annealed } \\
190^{\circ} \mathrm{C}, 0.5 \mathrm{~h}\end{array}$ & $\begin{array}{l}\text { annealed } \\
230^{\circ} \mathrm{C}, 8.0 \mathrm{~h}\end{array}$ \\
$\begin{array}{l}\text { Density } \\
\text { (g cm }\end{array}$ & & & & \\
\hline
\end{tabular}

intensities for each sample were recorded by a step scanning procedure in the range of $6^{\circ}<2 \theta<145^{\circ}$. Intensities for the lower scattering angles, i.e., $2 \theta<6^{\circ}$, were obtained by extrapolating the experimental curve smoothly to zero at zero scattering angle.

Afterwards, the raw intensity data were corrected for experimental factors, including background air scattering, absorption, polarization, and multiple scattering, according to standard methods ${ }^{7-10}$. The corrected intensity data, $I_{\text {expt }}$ were then normalized using the equation:

$$
\int \sum_{i}\left(x_{i} f_{i}^{2}+x_{i} I_{i}\right) \mathrm{d} s=\partial \int I_{\text {expl }} \mathrm{d} s
$$

where $x_{i}$ is the atomic fraction, $f_{i}$ the scattering factor, and $I_{i}$ the Compton scattering of the $i$-type atom, $s=(4 \pi / \lambda) \sin \theta$, and $\partial$ is the normalization constant. Since the polymers used were random copolymers, hypothetical chemical units of $\left(\mathrm{C}_{9.1} \mathrm{H}_{6.8} \mathrm{O}_{3.4}\right)$ for 70 PET/30 PHB and $\left(\mathrm{C}_{8.2} \mathrm{H}_{5.6} \mathrm{O}_{2.8}\right)$ for $40 \mathrm{PET} / 60 \mathrm{PHB}$ were assumed in the analysis based on the starting compositions of the copolymers.

The Fourier analysis of scattering intensities for a system containing several different types of atoms, in this case $\mathrm{C}, \mathrm{H}$, and $\mathrm{O}$, has been given by Waser and Schomaker ${ }^{11}$, discussed by Pings and Waser ${ }^{12}$, and applied by Longman and coworkers ${ }^{3,13}$ and Gupta and Yeh ${ }^{4}$. Following this analysis, the $D R D F, 4 \pi r^{2} \bar{\rho} H(r)$, for each copolymer sample was derived according to the equations:

$$
\begin{aligned}
4 \pi r^{2} \bar{\rho} H(r) & =\frac{2 r}{\pi} \int_{0}^{s_{\max }} s i(s) \sin s r \mathrm{~d} s \\
i(s) & =\left(I_{\mathrm{coh}}-\sum_{i} x_{i} f_{i}^{2}\right) /\left(\sum_{i} x_{i} f_{i}\right)^{2}
\end{aligned}
$$

where $\bar{\rho}$ is the average atomic density, $s_{\max }=16 \AA^{-1}$, and $I_{\text {coh }}$ is the coherent intensity obtained by subtracting Compton scattering from the normalized intensity data. The term $\sum_{i} x_{i} f_{i}^{2}$ is not strongly dependent on the way of defining the hypothetical chemical units since differences in $\sum_{i} x_{i} f_{i}^{2}$ values between PET and PHB segments are always small (within $\sim 1-4 \%$ ). The obtained $D R D F$ was further smoothed beyond its second peak by multiplying a damping factor, $\exp \left(-0.03 \mathrm{~s}^{2}\right)$, by $i(s)$. Possible errors in the scattering factors were also removed by adjusting the $D R D F$ curve below $\sim 1 \AA$ to a straight line having the theoretically expected slope of $-4 \pi \bar{\rho}$ (refs. 9 and 10 ).
Further discussions on proper construction of reliable $D R D F$ have been given previously by examining all the available literature information ${ }^{4,6}$.

\section{RESULTS AND DISCUSSION}

The corrected and normalized WAXS intensities for the quenched $70 \mathrm{PET} / 30 \mathrm{PHB}$ and $40 \mathrm{PET} / 60 \mathrm{PHB}$ copolymers are shown in Figure 1. Similar to most of the amorphous polymers, three peaks are present at $21.0^{\circ}$, $43^{\circ}$, and $83^{\circ} 2 \theta$ for the $70 \mathrm{PET} / 30 \mathrm{PHB}$ and at $20.2^{\circ}, 43^{\circ}$, and $83^{\circ}$ for the $40 \mathrm{PET} / 60 \mathrm{PHB}$. The WAXS patterns comprise no Bragg reflections, indicating the structure of the copolymer samples is noncrystalline. A comparison of the WAXS data of 70 PET/30 PHB and glassy 100 PET $/ 0$ PHB shows that the two polymers have very similar patterns in both peak intensity and position ${ }^{4}$. For 40 PET/60 PHB the intensity of the principal peak at $20.2^{\circ}$ is higher than that of the glassy $100 \mathrm{PET} / 0 \mathrm{PHB}$ by approximately $50 \%$. Also, the peak position is shifted from $20.2^{\circ}$ to $21.2^{\circ}$ when the PHB content is varied from 60 to $0 \mathrm{~mol} \%$ in the polymers. The other two maxima at $43^{\circ}$ and $83^{\circ}$ are virtually not affected by the composition.

The WAXS data for annealed copolymer samples are shown in Figure 2. It is seen that annealing of the amorphous $70 \mathrm{PET} / 30 \mathrm{PHB}$ copolymer results in splitting of the $21.0^{\circ}$ peak into three sharp reflections at $18.0^{\circ}$ (Bragg spacing $d=4.93 \AA$ ), $22.2^{\circ}(d=4.00 \AA)$, and $25.3^{\circ}(d=3.52 \AA)$. Similarly, three reflections at $19.7^{\circ}$ $(d=4.51 \AA), 20.7^{\circ}(d=4.29 \AA)$, and $22.4^{\circ}(d=3.97 \AA)$ are observed in the WAXS pattern for partially crystallized 40 PET/60 PHB. The peaks at $43^{\circ}$ and $83^{\circ}$ are unaffected by the thermal treatment for both copolymers.

The resultant $D R D F$ curves for quenched and annealed copolymers are shown in Figures 3 and 4 , respectively. For amorphous $70 \mathrm{PET} / 30 \mathrm{PHB}$ prominent peaks at 1.4 , 2.5 , and $4.7 \AA$ and very weak peaks at $6.4,8.6,10.7,12.9$, and $14.9 \AA$ are observed. The $D R D F$ for amorphous 40 PET/60 PHB copolymer shows nine well-shaped peaks at

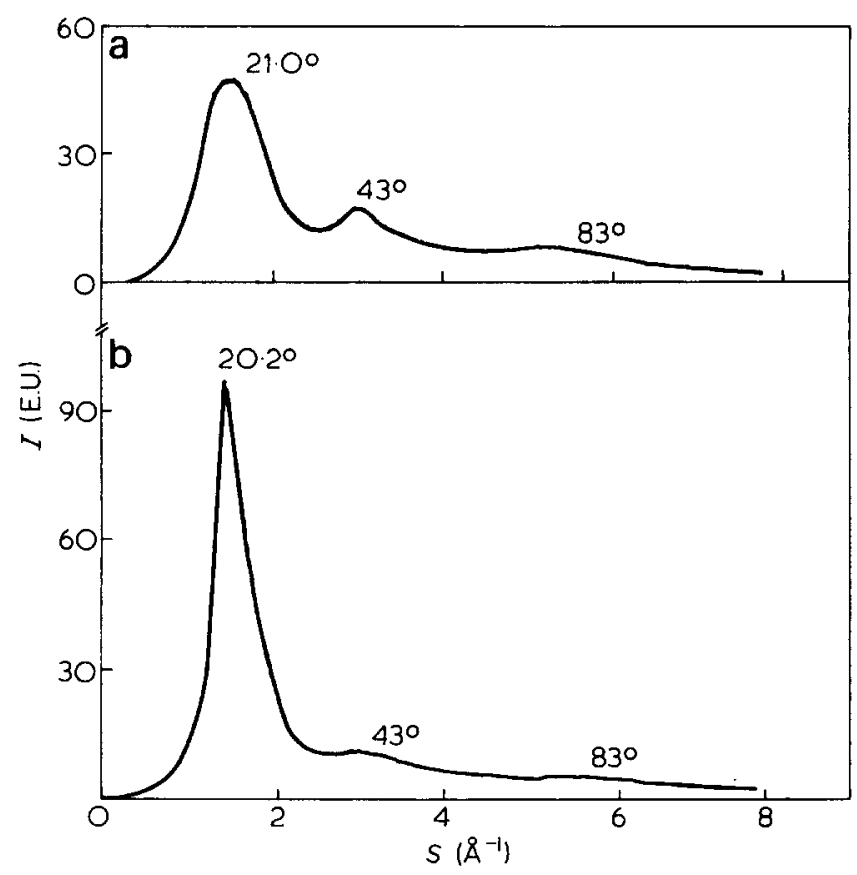

Figure 1 Corrected and normalized experimental WAXS data for quenched (a) 70 PET/30 PHB and (b) 40 PET/60 PHB 
$1.5,2.5,5.1,9.8,14.2,18.9,23.2,27.5$, and $31.7 \AA$. The results of annealing are shown by the presence of additional and prominent $D R D F$ peaks up to $40-50 \AA$ for the two partially crystalline samples. According to previous calculations of the intramolecular distances and their contributions to the local density fluctuation in polymers, the $D R D F$ curve for glassy $100 \mathrm{PET} / 0 \mathrm{PHB}$ consists of intramolecular peaks at $\sim 1.5$ and $2.5 \AA$ and intermolecular peaks beyond the radial distance of $\sim 4.5$

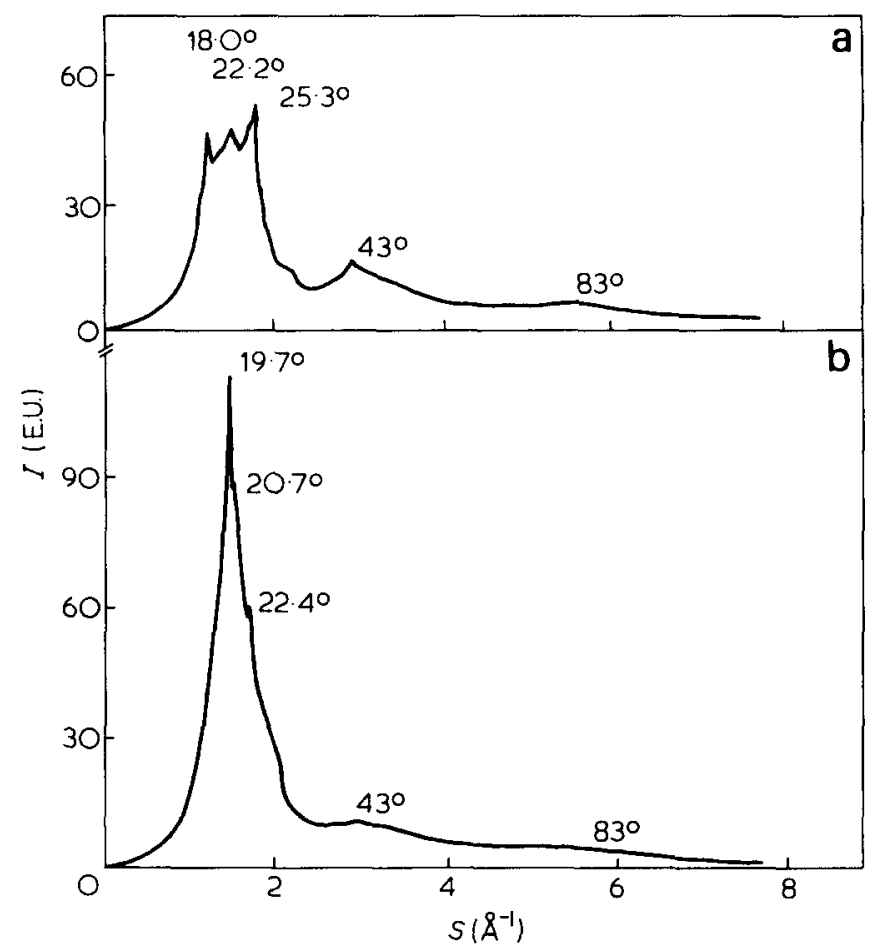

Figure 2 Corrected and normalized experimental WAXS data for annealed (a) $70 \mathrm{PET} / 30 \mathrm{PHB}$ and (b) $40 \mathrm{PET} / 60 \mathrm{PHB}$

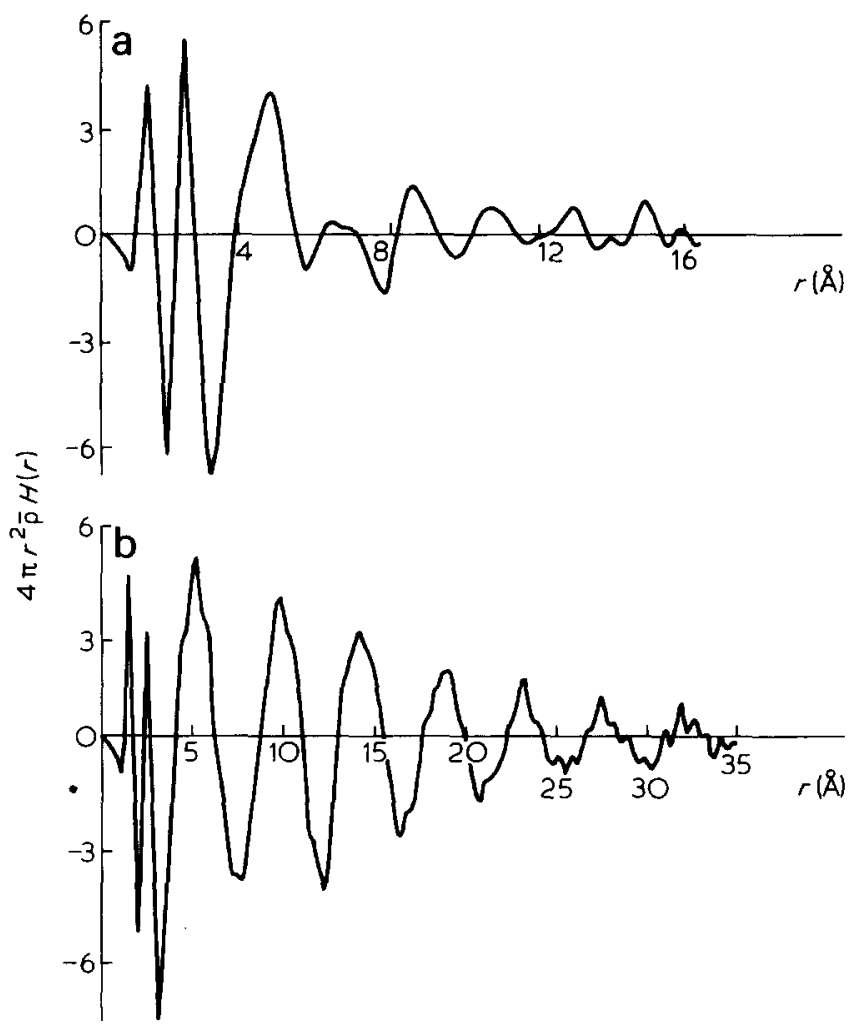

Figure 3 DRDF curves for quenched (a) $70 \mathrm{PET} / 30 \mathrm{PHB}$ and (b) 40 PET/60 PHB

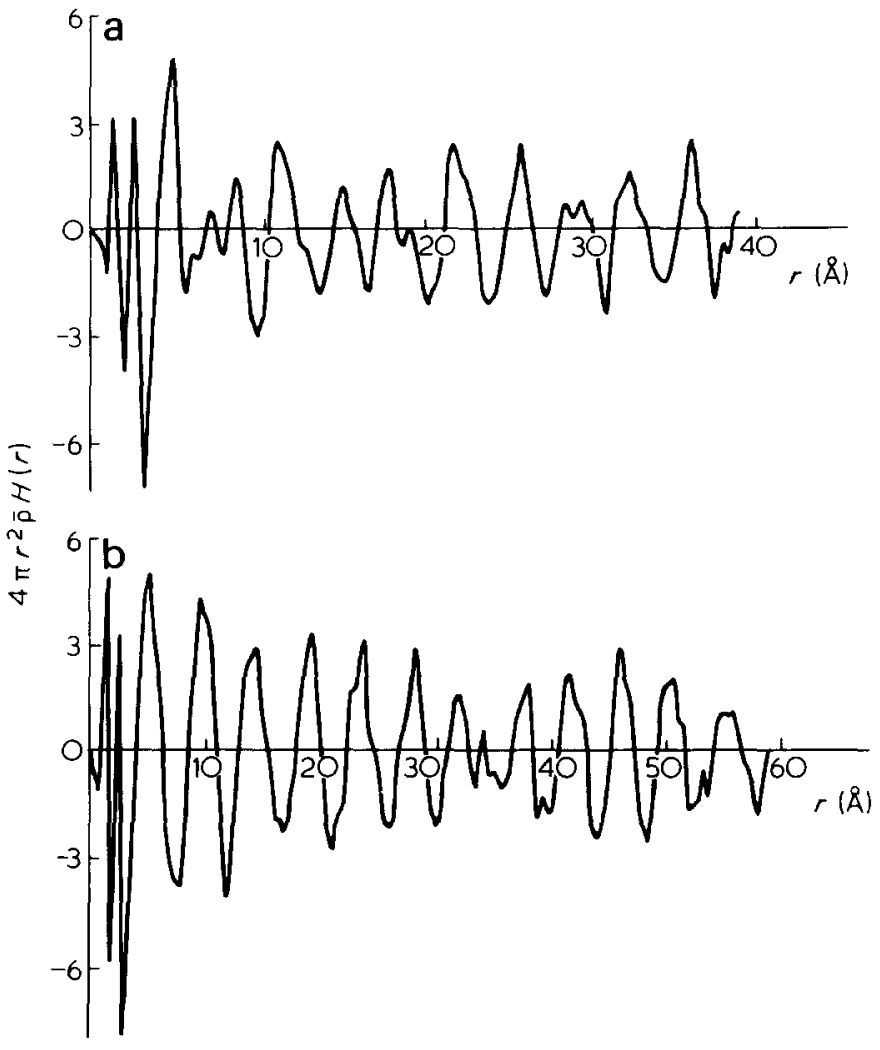

Figure 4 DRDF curves for annealed (a) $70 \mathrm{PET} / 30 \mathrm{PHB}$ and (b) 40 PET/60 PHB

$\AA^{3,4}$. In order to ascertain the intermolecular structural changes caused by incorporating PHB moieties into the PET backbone, the present study is focused on examining the $D R D F$ curves beyond $4.5 \AA$. The positions and heights of these intermolecular DRDF peaks are given in Table 2 for amorphous and partially crystallized $100 \mathrm{PET} / 0$ $\mathrm{PHB}^{4}, 70$ PET/30 PHB, and 40 PET/60 PHB.

The $D R D F$ results of glassy and partially crystalline 100 PET/0 PHB obtained by Gupta and Yeh ${ }^{4}$ have led to the suggestion of a highly distorted nematic lateral ordering in the amorphous polymer. The presence of local molecular organization was also suggested previously by Yeh and $\mathrm{Geil}^{14}$ based on dark field electron microscopy studies on thin polyester films. In this study the $D R D F$ curve for amorphous $70 \mathrm{PET} / 30 \mathrm{PHB}$ is found to be very similar to that for the glassy $100 \mathrm{PET} / 0 \mathrm{PHB}$ as shown in Table 2. The result indicates that a similar local structure is present in the amorphous $70 \mathrm{PET} / 30 \mathrm{PHB}$ copolymer. Additionally, the existence of local alignment of chain segments is suggested by the significant enhancement of the intermolecular $D R D F$ peaks at $4.7,10.7$, and $14.9 \AA$ when the copolymer is annealed. The periodicity of $\sim 5 \AA$ observed from these peaks represents the average distance between the more-or-less parallel neighbouring chains. The $D R D F$ results therefore suggest the presence of a short range molecular organization of $\sim 15 \AA$ in the quenched 70 PET/30 PHB copolymer. The molecular alignment is markedly improved by annealing of the copolymer as shown by the appearance of prominent and additional periodic intermolecular peaks up to a much higher radial distance in the $D R D F$ for annealed 70 PET/30 PHB sample.

For amorphous 40 PET/60 PHB a periodicity of $\sim 4.5$ $\AA$ is observed from the seven well-shaped intermolecular $D R D F$ peaks given in Table 2, suggesting the existence of 
Table 2 Description of the intermolecular DRDF peaks

\begin{tabular}{|c|c|c|c|c|c|c|c|c|c|c|c|}
\hline \multicolumn{2}{|c|}{$\begin{array}{c}100 \text { PET/O PHB* } \\
\text { (quenched) }\end{array}$} & \multicolumn{2}{|c|}{$\begin{array}{l}100 \mathrm{PET} / 0 \mathrm{PHB}{ }^{*} \\
\left(190^{\circ} \mathrm{C}, 0.25 \mathrm{~h}\right)\end{array}$} & \multicolumn{2}{|c|}{$\begin{array}{c}70 \mathrm{PET} / 30 \mathrm{PHB} \\
\text { (quenched) }\end{array}$} & \multicolumn{2}{|c|}{$\begin{array}{l}70 \mathrm{PET} / 30 \mathrm{PHB} \\
\left(190^{\circ} \mathrm{C}, 0.5 \mathrm{~h}\right)\end{array}$} & \multicolumn{2}{|c|}{$\begin{array}{c}40 \mathrm{PET} / 60 \mathrm{PHB} \\
\text { (quenched) }\end{array}$} & \multicolumn{2}{|c|}{$\begin{array}{l}40 \mathrm{PET} / 60 \mathrm{PHB} \\
\left(230^{\circ} \mathrm{C}, 8.0 \mathrm{~h}\right)\end{array}$} \\
\hline$P$ & $\boldsymbol{H}^{\dagger}$ & $P$ & $H$ & $P$ & $H$ & $P$ & $H$ & $P$ & $H$ & $P$ & $H$ \\
\hline 4.8 & 4.1 & 4.8 & 5.3 & 4.7 & 4.0 & 4.7 & 4.9 & 5.1 & 5.1 & 5.0 & 5.0 \\
\hline 6.8 & 0.6 & 7.3 & 2.2 & 6.4 & 0.3 & 7.1 & 0.6 & - & - & - & - \\
\hline 8.5 & 1.5 & 8.3 & 1.7 & 8.6 & 1.2 & 8.5 & 1.5 & & & & 42 \\
\hline 11.1 & 0.6 & 11.3 & 3.7 & 10.7 & 0.6 & 11.0 & 2.5 & 9.8 & 4.1 & 9.7 & 4.2 \\
\hline 12.5 & 0.5 & - & - & 12.9 & 0.6 & - & - & - & - & - & - \\
\hline 15.4 & 0.2 & 14.5 & 0.5 & 14.9 & 0.8 & 14.8 & 1.4 & 14.2 & 3.1 & 14.4 & 2.8 \\
\hline 17.4 & 0.6 & 17.7 & 4.5 & - & - & 17.4 & 1.8 & 18.9 & 2.0 & 19.1 & 3.3 \\
\hline- & - & 21.7 & 2.2 & - & - & 21.5 & 2.5 & 23.2 & 1.7 & 23.5 & 3.1 \\
\hline- & - & 24.3 & 1.3 & - & - & 25.6 & 2.5 & 275 & & 278 & 30 \\
\hline- & - & 28.2 & 2.4 & - & - & 28.3 & 0.9 & $\begin{array}{l}27.5 \\
31.7\end{array}$ & $\begin{array}{l}1.2 \\
0.9\end{array}$ & $\begin{array}{l}27.8 \\
320\end{array}$ & 3.0 \\
\hline- & - & 31.6 & 1.2 & - & - & 32.2 & 1.7 & 31.7 & 0.9 & 32.0 & 1.5 \\
\hline- & - & - & - & - & - & 35.9 & 2.5 & - & - & 37.9 & 1.9 \\
\hline- & - & - & - & - & - & - & - & - & - & 41.6 & 2.2 \\
\hline- & - & - & - & - & - & - & - & - & - & 45.9 & 2.8 \\
\hline- & - & - & - & - & - & - & - & - & - & 50.5 & 2.0 \\
\hline
\end{tabular}

* Data taken from ref. 4 and recalculated by applying the damping factor exp $\left(-0.03 s^{2}\right)$

$t$ Peak position $P$ and peak height $H$

lateral ordering of $\sim 30 \AA$ in the copolymer. The periodic peaks are explained by the higher concentration of those interatomic distances resulting from more-or-less parallel neighbouring chains. Similar to amorphous 100 PET/0 $\mathrm{PHB}^{4}$ and $70 \mathrm{PET} / 30 \mathrm{PHB}$, the lateral alignment of chain segments is improved by annealing as shown by increases in number of intermolecular peaks and in intensities of the higher distance $D R D F$ peaks. As indicated by McFarlane and coworkers ${ }^{2}$, the 40 PET/60 PHB copolymer can be classified as a liquid crystalline material. The finding of lateral molecular alignment in this copolymer from the present $D R D F$ results is consistent with the basic idea of the low molecular weight liquid crystals. The liquid crystalline polymers have been recognized as a special type of polymeric system occupying a position intermediate between amorphous and crystalline polymers ${ }^{15}$. Although this paper is not intended for exploring the liquid crystalline characteristics of the new copolymer, it is of interest to note that the extent of lateral ordering of $40 \mathrm{PET} / 60 \mathrm{PHB}$ falls between those of the typical amorphous and crystalline polymers as revealed by the $D R D F$ analysis.

Further, the study has shown that $D R D F$ curves for amorphous $100 \mathrm{PET} / 0 \mathrm{PHB}$ and $70 \mathrm{PET} / 30 \mathrm{PHB}$ are very similar. This result indicates that the PHB content up to $30 \mathrm{~mol} \%$ is insufficient to cause any major change in molecular alignment of the polymers. The structural similarity is in agreement with the very small property difference observed previously for the copolymers in this composition range $e^{1,2}$. By increasing the PHB content from 30 to $60 \mathrm{~mol} \%$, a substantial improvement in the lateral chain alignment in the copolymers is shown by the increase in the extent of ordering from 15 to $30 \AA$. The improvement can be attributed to the modification of the chemical configuration of macromolecules due to the incorporation of more planar para-substituted PHB moieties into the polyester. The structural change explains the reported profound differences in melt viscosity and density between 70 PET/30 PHB and 40 PET/60 PHB $^{1,2}$.

\section{CONCLUSION}

The presence of locally aligned chain segments in the copolymers containing 30 and $60 \mathrm{~mol} \% \mathrm{PHB}$ is suggested based on the DRDF study of quenched and annealed copolymer samples. The extent of the lateral molecular alignment is $\sim 15 \AA$ for amorphous $70 \mathrm{PET} / 30 \mathrm{PHB}$ and $\sim 30 \AA$ for 40 PET $/ 60$ PHB. The structural modification revealed by the DRDF results is consistent with the property changes caused by varying the PHB content of the copolymers.

\section{ACKNOWLEDGEMENTS}

We are grateful for the support of this research by the National Science Foundation and Macromolecular Research Center of the University of Michigan. We also wish to thank Dr W. J. Jackson, Jr., of Tennessee Eastman Company for supplying the copolymers used in this study.

\section{REFERENCES}

1 Jackson, Jr., W. J. and Kuhfuss, H. F. J. Polym. Sci., Polym. Chem. Edn. 1976, 14, 2043

2 McFarlane, F. E., Nicely, V. A. and Davis, T. G. in 'Contemporary Topics in Polymer Science', (Eds. E. M. Pierce and J. R. Schaefgen), Plenum, New York, 1977, Vol. 2, p 109

3 Longman, G. W., Sheldon, R. P. and Wignall, G. D. J. Mater. Sci. $1976,11,1339$

4 Gupta, M. R. and Yeh, G. S. Y. J. Macromol. Sci.-Phys. 1978, B15, 119

$5 \quad$ Wang, C. S. and Yeh, G. S. Y. Polymer 1977, 18, 1085

6 Wang, C. S. and Yeh, G. S. Y. J. Macromol. Sci.-Phys. 1978, B15, 107

7 Klug, H. P. and Alexander, L. E. 'X-ray Diffraction Procedures', John Wiley, New York, 1974

8 Furukawa, K. Rep. Prog. Phys. 1962, 25, 395

9 Wecker, S. M. MS Thesis Northwestern University, 1970

10 Wecker, S. M., Davidson, T. and Cohen, J. B. J. Mater. Sci. 1972, 7,1249

11 Waser, J. and Schomaker, V. Rev. Mod. Phys. 1953, 25, 671

12 Pings, C. J. and Waser, J. J. Chem. Phys. 1968, 48, 3016

13 Wignall, G. D. and Longman, G. W. J. Mater. Sci. 1973, 8, 1439

14 Yeh, G.S. Y. and Geil, P. H.J. Macromol. Sci.-Phys. 1967, B1, 235

15 Shibayev, V. P. and Plate, N. A. Polym. Sci. USSR 1977, 19, 1065 